\title{
VALIDATION OF RECOGNITION OF STROKE IN THE EMERGENCY ROOM SCALE IN TURKISH POPULATION AND COMPARISON OF ITS EFFICIENCY WITH FACE-ARM-SPEECH TEST
}

\author{
Nurdan Yılmaz Şahin ${ }^{1}$, Mehmet Okumuş², Isa Baspınar', Burak Demirci ${ }^{3}$, Ahmet Çelik ${ }^{1}$ \\ ${ }^{1}$ Şanlıurfa Eğitim ve Araştırma Hastanesi, Şanlıurfa, Turkey \\ ${ }^{2}$ Department of Emergency Medicine, University of Health Sciences, Ankara Training and Research Hospital, Ankara, Turkey \\ ${ }^{3}$ Bağcılar Training and Research Hospital, Istanbul, Turkey
}

\begin{abstract}
INTRODUCTION: Various risk scores were developed to recognize acute stroke easily and to start treatment right away in the emergency departments. Although the Recognition of Stroke in the Emergency Room (ROSIER) score used for this purpose is indicated better than the other scoring systems, it is expressed that it will be able to have social differentiations. In this study, we targeted to research validation of the ROSIER scale and to compare its efficiency with Face-Arm-Speech Test (FAST), another stroke diagnosis method, for the patients who applied to the emergency department with the stroke or transient ischemic attack symptoms.

MATERIAL AND METHODS: The patients who reported to the emergency department with the suggestive symptoms or findings of stroke and were above 18 years of age were included in the study. The study forms were filled out by the emergency medicine specialist or the senior emergency medical assistant after the patients were evaluated, and then they were consulted by the neurology specialist. The final diagnosis, which was established after the clinical evaluation and necessary imaging done by the neurology specialists, was accepted as a standard reference.
\end{abstract}

RESULTS: A total of 335 patients, including 168 (50.1\%) females, were included in the study. The sensitivity was $68.5 \%$, specificity was $79.0 \%$, Positive Predictive Value (PPV) was $78.7 \%$, NPV (Negative Predictive Value) was $68.9 \%$, and test validity was $73.4 \%$ for the ROSIER scale. For the FAST scale the sensitivity was $63.5 \%$, specificity was $88.5 \%$, PPV was $86.3 \%$, NPV was $68.1 \%$, and test validity was $75.2 \%$.

CONCLUSION: In the present study, it was seen that the ROSIER scale could be used in separating the patients with CVO (cerebrovascular accident) from the patients who applied with the similar clinical findings. However, FAST was superior because its specificity and PPV were higher and its practicability was easier than the ROSIER.

KEY WORDS: emergency department, transient ischemic stroke, stroke, FAST score, ROSIER score

Disaster Emerg Med J 2021; 6(3): 112-118

ADDRESS FOR CORRESPONDENCE:

Nurdan Yılmaz Şahin, Şanlıurfa Mehmet Akif Inan Eağitim Araştırma Hastanesi, Şanlıurfa, Turkey

e-mail: nrdnshn84@gmail.com 


\section{INTRODUCTION}

Early and true diagnosis of the stroke is important for the timing of early intervention and positive result [1]. The pre-hospital stroke evaluation tools are a help in the diagnosis to determine pre-hospital suspicious of stroke [1]. A successful pre-hospital stroke evaluation method should be fast, easy-touse, and should provide a productive and effective evaluation [2].

Early thrombolytic treatment was shown to be reliable, and decreased mortality and morbidity in the acute ischemia patients. However, it was reported that two out of three of the patients delayed receiving a diagnosis because of not being provided proper triage $[3,4]$. After this process, the severe problems such as long term disability, impaired quality of life, and overuse of financial resources happen $[5,6]$. Different risk scores were developed to recognize acute CVO easily and to start treatment right away in the emergency departments [7, 9]. The ROSIER score is one of the scoring systems used in the UK in particular [10]. Although it is stated to be better than the scorings used in this subject, it is expressed that it will be able to have social differentiations $[11,12]$.

The Recognition of Stroke in the Emergency Room (ROSIER) scale was developed in a UK population in 2005 to determine acute stroke early and to facilitate proper transfer. Its efficiency was supported by the scientific studies $[1,2,11]$. It was shown that it provided an $11 \%$ increase in the sensitivity than the Face-Arm-Speech Test (FAST) used previously and decreased unnecessary transfers for the stroke team significantly [11]. In this study, the value and usability of the ROSIER scale were researched in the Turkish population and in addition to this; the comparison of its effectiveness was conducted with the previously used FAST scale.

\section{MATERIAL AND METHODS}

This study was prospectively performed in the Emergency Medicine Clinic of Ankara Training and Research Hospital between January 15, 2016 and July 15, 2016 after obtaining the approval of the ethics committee of the Training, Planning and Coordination Committee of the Ankara Training and Research Hospital of $1^{\text {st }}$ Regional Secretariat General of the Ankara Public Hospitals Association of RfT Ministry of Health Public Hospitals Administration of Turkey with number 0622 on December 16, 2015. This study was performed in a tertiary hospital that has 300000 emergency department patient applications annually.

The patients who applied to the emergency department with the suggestive symptoms or findings of transient ischemic attack or stroke and were above 18 years of age were included in the study within the study period. The patients who had traumatic brain damage caused by the external reasons such as falling or motor vehicle accidents, did not have medical records, had subdural/epidural/subarachnoid bleeding, and whose first entries were not in the emergency department, were excluded. The inclusion and exclusion criteria for the study were conducted in the same way with the original article to make a significant comparison. The consent was obtained from the patients for those who accepted to participate in the study, and from the immediate family for those who did not give consent. The patients were taken into the study after they were evaluated by the emergency medicine specialist or senior emergency medical assistant participating in the study, and the necessity of the neurology consultation was determined. In conclusion, all patients having a stroke suspicion were consulted by a neurology specialist. The final diagnosis, which was established after the clinical evaluation and necessary imaging done by the neurology department, was accepted as a standard reference for the diagnosis in this study. After filling out forms of the patients included in the study, the data were controlled and their scores were calculated. The patients, who had data deficiency that would prevent the calculation of the scores, were excluded from the study in this stage. 335 patients were taken into statistical analysis after all those stages (Fig. 1).

The demographic and clinical data, physical examination findings, laboratory results, and last conditions of the patients were recorded in the constituted forms. The first part of the study questionnaires consisted of the patients demographic information questions, complaint and start time, comorbid diseases, habits, vital findings, blood glucose level, and physical examination findings. The second part contained imaging results of the patient, last diagnosis of the patient and evaluations according to the FAST and ROSIER scores.

The study data were recorded in a computer and evaluated using SPSS (Statistical Package for Social Sciences) Windows 20.0 program. The mean and standard deviation were used in showing the 


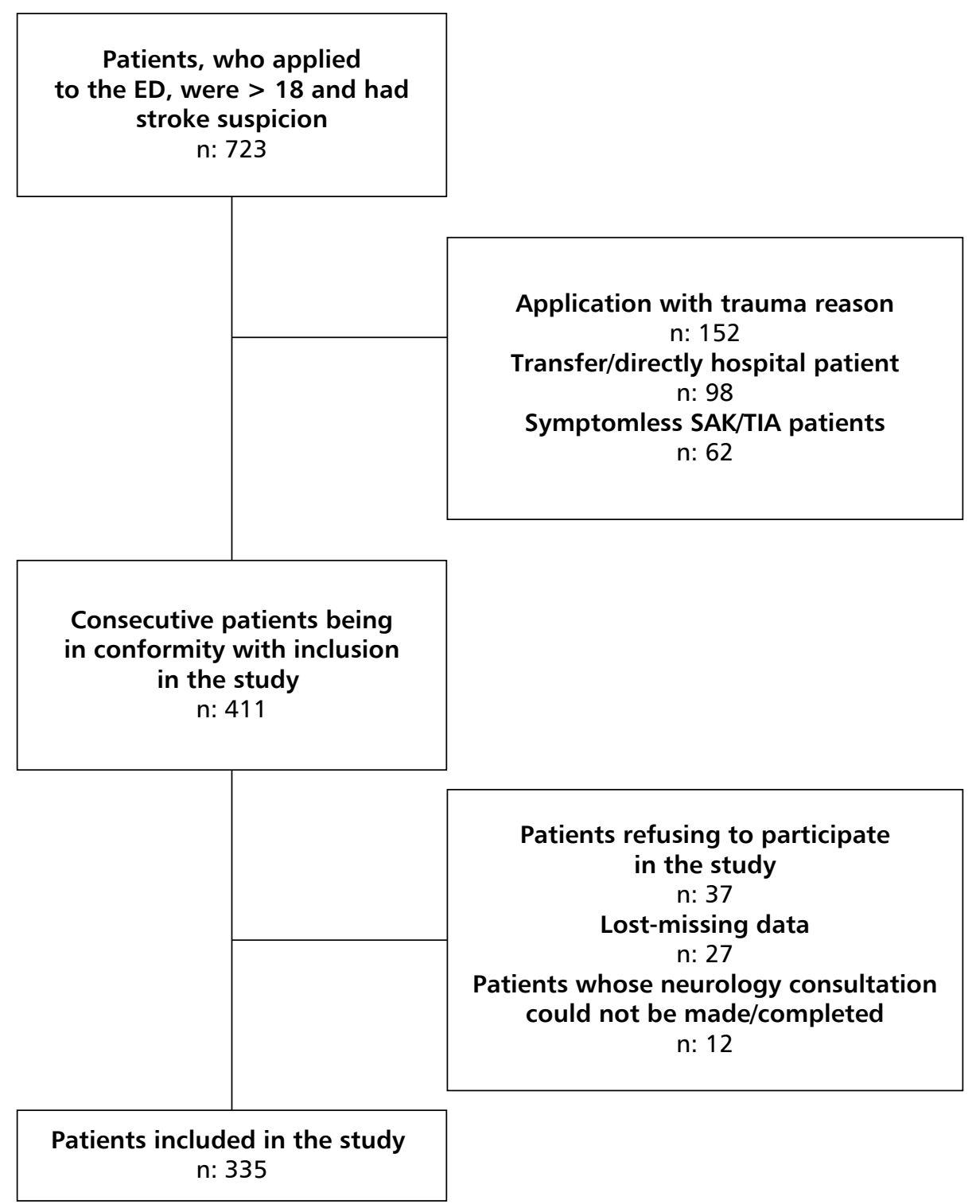

FIGURE 1. Patient Flow Chart

quantitative parametric data. The median and interquartile ranges (IQR) were used in showing the non-parametric data. The case number and percentage expressions were used in showing the qualitative data. Analysis of the non-parametric data was evaluated by the Mann-Whitney $U$ test between the groups. The categorical variables were evaluated by the Pearson chi-square test and the Fisher's exact test. The sensitivity, specificity, Positive Predictive Value (PPV) and Negative Predictive Value (NPV) of the variables and validity of the tests were calculated. The results were evaluated in a 95\% Confidence Interval and $\mathrm{p}<0.05$ significance level.

\section{RESULTS}

A total of 335 patients, including 168 (50.1\%) females, were included in the study. The mean age of the patients was 67 years (IQR: 27). The mean age of the patients with CVO was 69.5 years (IQR: 23) and the mean age of the patients without CVO was 64 years (IQR: 33). The mean age of the patient with CVO was significantly determined higher $(p=0.001)$ (Tab. 1). 95 (53.4\%) of the patients with CVO and 72 (45.9\%) of the patients without CVO were male. The gender was similar in both patient groups $(p=0.170)($ Tab. 2$)$. 
Table 1. Age comparison of the groups

\begin{tabular}{|l|c|c|c|c|}
\hline & $\begin{array}{c}\text { Total }(n=335) \\
\text { Median (IQR) }\end{array}$ & $\begin{array}{c}\text { CVO }(n=178) \\
\text { Median (IQR) }\end{array}$ & $\begin{array}{c}\text { Not CVO }(n=157) \\
\text { Median (IQR) }\end{array}$ & $p$ \\
\hline Age & $67(27)$ & $69.5(23)$ & $64(33)$ & $0,001 *$ \\
\hline
\end{tabular}

*the Mann-Whitney U Test; CVO — cerebrovascular accident; IQR — interquartile ranges

Table 2. Gender comparison of the groups

\begin{tabular}{|l|c|c|c|c|}
\hline & Total $(n=335)(\%)$ & CVO $(n=178)(\%)$ & Not CVO $(n=157)(\%)$ & $p^{*}$ \\
\cline { 1 - 4 } Male & $167(49.9)$ & $95(53.4)$ & $72(45.9)$ & \multirow{2}{*}{0.170} \\
\hline Female & $168(50.1)$ & $83(46.6)$ & $85(54.1)$ & \\
\hline
\end{tabular}

*Pearson chi-square test; CVO — cerebrovascular accident

Table 3. Comparison of time of reporting of the groups
\begin{tabular}{|l|c|c|c|c|}
\hline & Total $(n=335) n(\%)$ & CVO $(n=178) n(\%)$ & Not CVO $(n=157) n(\%)$ & $p^{*}$ \\
\hline $0-12$ hour & $99(29.6)$ & $60(33.7)$ & $39(24.8)$ & $84(53.5)$ \\
\hline $13-24$ hour & $175(52.2)$ & $91(51.1)$ & $27(17.2)$ & 0.156 \\
\hline $1-3$ days & $41(12.2)$ & $14(7.9)$ & $5(3.2)$ & \\
\hline $4-7$ days & $14(7.9)$ & $9(5.1)$ & $2(1.3)$ & \\
\hline $7+$ days & $6(1.8)$ & $4(2.2)$ & & \\
\hline
\end{tabular}

${ }^{*}$ The Fisher's exact test; $\mathrm{CVO}$ — cerebrovascular accident

Table 4. Comparison of comorbid diseases and social habits of the groups
\begin{tabular}{|l|c|c|c|c|}
\hline & Total $(n=335)(\%)$ & CVO $(n=178)(\%)$ & Not CVO (n=157) (\%) & $p$ \\
\hline HT & $249(74.3)$ & $153(86.0)$ & $96(61.1)$ & $<0.001^{*}$ \\
\hline KAH & $167(49.9)$ & $106(59.6)$ & $62(39.5)$ & $<0.001^{*}$ \\
\hline Dm & $93(27.8)$ & $56(31.5)$ & $37(23.6)$ & $0.107^{*}$ \\
\hline CVO & $40(11.9)$ & $29(16.3)$ & $11(7.0)$ & $0.009^{*}$ \\
\hline AF & $27(8.1)$ & $18(10.1)$ & $9(5.7)$ & $0.142^{*}$ \\
\hline Dyslipidemia & $21(6.3)$ & $14(7.9)$ & $7(4.5)$ & $0.199^{*}$ \\
\hline KBY & $14(4.2)$ & $6(3.4)$ & $8(5.1)$ & $0.431^{*}$ \\
\hline Other & $43(12.8)$ & $15(8.4)$ & $28(17.8)$ & $0.010^{*}$ \\
\hline Cigarette & $87(26.0)$ & $43(24.2)$ & $44(28.0)$ & $0.420^{*}$ \\
\hline Alcohol & $9(2.9)$ & $4(2.2)$ & $5(3.2)$ & $0.739^{* *}$ \\
\hline
\end{tabular}

*Pearson's chi-square test; **Fisher's exact test

While $33.7 \%$ of the patients with CVO reported after $0-12$ hours, and $51.1 \%$ of them reported after $13-24$ hours, $24.8 \%$ of the patients without CVO reported after $0-12$ hours, and $53.5 \%$ of them reported after 13-24 hours from the onset of symptoms (Tab. 3).

While the HT, KAH and CVO frequencies of the patients with CVO were significantly higher, the other comorbidity frequencies of the patients without CVO were significantly higher (Tab. 4). No differences were determined in terms of the DM,
$A F$, dyslipidemia and $\mathrm{KBY}$ frequencies between the groups. No differences were determined in terms of the cigarette and alcohol use frequencies between the groups (Tab. 4). While ischemia and intraparenchymal hematoma were determined in CT findings of the patients with CVO at the rate of $12.9 \%$ $(n=23)$ and $2.8 \%(n=5)$ respectively, no findings were determined at the rate of $84.3 \%(n=153)$ in the CT. The diagnosis was made by the diffusion MRI for the patients who did not have findings in the CT (Tab. 5). When the patients with CVO were 


Table 5. Comparison of tomography findings of the
groups
\begin{tabular}{|l|c|c|}
\hline & $\begin{array}{c}\text { CVO } \\
(n=178)(\%)\end{array}$ & $\begin{array}{c}\text { Not CVO } \\
(\mathrm{n}=157)(\%)\end{array}$ \\
\hline Normal & $153(84.3)$ & $137(89.1)$ \\
\hline Ischemia & $23(12.9)$ & 0 \\
\hline $\begin{array}{l}\text { Intraparenchymal } \\
\text { hematoma }\end{array}$ & $5(2.8)$ & 0 \\
\hline Mass & 0 & $5(3.2)$ \\
\hline Bleeding in mass & 0 & $3(2.0)$ \\
\hline Aneurysmatic bleeding & & $1(0.6)$ \\
\hline Mass + oedema & 0 & $2(1.3)$ \\
\hline Calcification & 0 & $1(0.6)$ \\
\hline Oedema & 0 & $4(2.6)$ \\
\hline Cystic structure & 0 & $1(0.6)$ \\
\hline
\end{tabular}

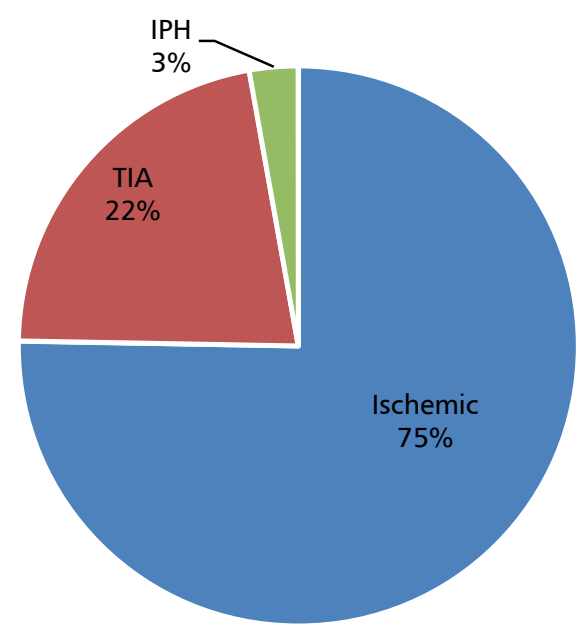

FIGURE 2. Sub-groups of the CVO patients; TIA — transient ischemic attack

considered together with the diffusion MRI, 75.3\% $(n=134)$ of the patients were ischemic CVO, 21.9\% of them were transient ischemic attack (TIA) and $2.8 \%(n=5)$ of them were intraparenchymal hematoma (Fig. 2).

The sensitivity and specificity of the ROSIER score were $68.5 \%$ and $79.0 \%$ in the CVO diagnosis, respectively, and the sensitivity and specificity of the FAST score were $63.5 \%$ and $88.5 \%$, respectively. While the sensitivity of the ROSIER score was higher, the specificity of the FAST score was higher (Tab. 6).

\section{DISCUSSION}

The age factor is known to be an irreversible risk factor in both ischemic stroke and hemorrhagic stroke
Table 6. Sensitivity, selectivity, PPV, and NPV of the ROSIER and FAST scores of the groups and validity levels of the tests

\begin{tabular}{|l|c|c|c|c|c|}
\hline & $\begin{array}{c}\text { Sensitivity } \\
(\%)\end{array}$ & $\begin{array}{c}\text { Selectivity } \\
(\%)\end{array}$ & $\begin{array}{c}\text { PPV } \\
(\%)\end{array}$ & $\begin{array}{c}\text { NPV } \\
(\%)\end{array}$ & $\begin{array}{c}\text { Validity } \\
(\%)\end{array}$ \\
\hline ROSIER & 68.5 & 79.0 & 78.7 & 68.9 & 73.4 \\
\hline FAST & 63.5 & 88.5 & 86.3 & 68.1 & 75.2 \\
\hline
\end{tabular}

FAST — Face-Arm-Speech Test; ROSIER — Recognition of Stroke in the Emergency Room

[13]. The mean age of the patients with CVO was expressed between 65-75 in the same way with our study $[1,11,14-17]$. While the mean age was determined as 67 in our study, the mean age of the patients with CVO was significantly detected higher than the patients without CVO. In addition to this, we are of the opinion that the CVO is seen in later ages since the comorbidities such as $\mathrm{HT}$, atherosclerosis, and DM increase especially with age, and the negative cardiovascular effects of changing hormone mechanisms become apparent especially in females in later ages.

It was expressed that the HT, DM, atherosclerotic cardiovascular disease, $\mathrm{AF}$, ischemic heart disease, and stroke history were the risk factors for the CVO $[13,14,18-20]$. While the HT, KAH and CVO frequencies of the patients with CVO were significantly higher in our study; no differences were determined between the groups in terms of the DM, AF, dyslipidemia and KBY frequencies. However, the DM was also high as a percentage in the group with CVO.

The male ratio was slightly higher in the patients with CVO in both the studies performed previously and our study. In our study, $53 \%$ of the patients with CVO were male. The male ratio was mostly stated as $53 \%$ and above in the previous studies, however, no differences were statistically expressed in terms of the gender for the patients who applied to the emergency department with the CVO symptoms [1, $11,17,21,22]$. We may indicate that there is not a difference between the groups since the increasing pathologies are similar in the upcoming ages in both genders.

In our study, it was specified that the applications in the first 24 hours were made at the rate of $85 \%$ for the patients with CVO and at the rate of $78 \%$ for the patients without CVO and those rates were similar. In the previous studies, it was specified that the applications in the first 24 hours were made at a higher rate for the patients with CVO $[11,16]$.

It was stated in the performed studies that the ROSIER score could be used in foreseeing the CVO 
$[1,11,17,19]$. Jackson et al. expressed in their study that the ROSIER score would be used in recognizing the CVO; however, its usability was partly limited since it was restrictive in evaluating the unconscious patients. The symptoms were better in the patients with TIA, and CVO was determined at the rate of $12 \%$ when the CVO was not expected for ROSIER score of 0 [20]. Jiang et al. stated in their study that the ROSIER score was a proper method in the differential diagnosis for the CVO; however, the method remained incapable in case where the patients had sequel CVO [1]. Brandler et al. expressed in two studies that the ROSIER score remained incapable in separating the seizure and syncope cases, although it was used in showing the stroke diagnosis $[23,24]$. In our study, the ROSIER score was seen successful in determining the CVO in cases where it was $\geq 1$. We are of the opinion that the ROSIER can be used in separating the CVO. In addition to this, the test excludes the CVO diagnosis in cases where the score was $\leq 0$; however, as it is in the other studies, determining the CVO in this score presence shows that the score has deficiencies.

Rudd et al. stated in their study that the sensitivity of ROSIER was $83-97 \%$, specificity was $18-93 \%$, PPV was $62-94 \%$ and NPV was 33-88\% [25]. Nor et al. specified in their study that the sensitivity of ROSIER was $87 \%$ and specificity was $41 \%$ [11]. Mao et al. determined in their study that the sensitivity of ROSIER was $77.7 \%$, specificity was $59.1 \%$, PPV was $94.2 \%$, NPV was $33.9 \%$, and test validity was $77 \%$ [16]. Whitely et al. specified that the sensitivity of ROSIER was $83 \%$, specificity was $44 \%$ and the study was repeatable [26]. Purrucker et al. stated in their study that the sensitivity of ROSIER was $80 \%$, specificity was $79 \%$, PPV was $59 \%$, and NPV was $91 \%$ in separating the patients with and without CVO [27]. In our study, the sensitivity was $69 \%$, specificity was $79 \%$, PPV was $79 \%$, and NPV was $69 \%$ for the ROSIER score. We are of the opinion that some of the findings taking place within the ROSIER score caused decrease for the sensitivity, specificity, PPV, and NPV since their definitions did not completely make and they stepped in the clinical findings for the CVO.

Rudd et al. stated in their study that the sensitivity of FAST was $62-94 \%$, specificity was 33-88\%, PPV was $62-89 \%$ and NPV was 48-93\% [25]. Purrucker et al. specified in their study that the sensitivity of FAST was $85 \%$, specificity was $68 \%$, PPV was $50 \%$, and NPV was $92 \%$ in separating the patients with and without CVO [27]. Fothergill et al. expressed that the ROSIER score was better than the FAST [2]. The sensitivity was $64 \%$, specificity was $89 \%$, PPV was $86 \%$, and NPV was $68 \%$ for the FAST score. The FAST score in our study is accordant with literature and gives similar results to the ROSIER score. However, we are of the opinion that FAST is superior, since its specificity and PPV are higher than in the case of ROSIER, and its application is easier.

\section{CONCLUSION}

The ROSIER score is a non-invasive and rapid test that can be used in separating the patients with CVO from the patients who reported to the emergency department with the same clinical findings. However, we are of the opinion that the FAST score is superior, since its specificity and PPV are higher than in the case of ROSIER, and its practicability is easier. In addition to this, we may say that it is required to bring the parameters to be checked to a more specific condition, or new parameters should be added, and further studies related to this subject have to be made in order to increase sensitivity, specificity, PPV, NPV, and validation of the ROSIER score.

\section{REFERENCES}

1. Jiang HI, Chan CPy, Leung Yk, et al. Evaluation of the Recognition of Stroke in the Emergency Room (ROSIER) scale in Chinese patients in Hong Kong. PLoS One. 2014; 9(10): e109762, doi: 10.1371/journal. pone.0109762, indexed in Pubmed: 25343496.

2. Fothergill RT, Williams J, Edwards MJ, et al. Does use of the recognition of stroke in the emergency room stroke assessment tool enhance stroke recognition by ambulance clinicians? Stroke. 2013; 44(11): 3007-3012, doi: 10.1161/STROKEAHA.13.000851, indexed in Pubmed: 24072006.

3. Nor AM, Davis J, Sen B, et al. The Recognition of Stroke in the Emergency Room (ROSIER) scale: development and validation of a stroke recognition instrument. Lancet Neurol. 2005; 4(11): 727-734, doi: 10.1016/S1474-4422(05)70201-5, indexed in Pubmed: 16239179.

4. Mingfeng He, Zhixin Wu, Qihong $\mathrm{G}$, et al. Validation of the use of the ROSIER scale in prehospital assessment of stroke. Ann Indian Acad Neurol. 2012; 15(3): 191-195, doi: 10.4103/0972-2327.99713, indexed in Pubmed: 22919191.

5. Goldstein LB, Bushnell CD, Adams RJ, et al. American Heart Association Stroke Council, Council on Cardiovascular Nursing, Council on Epidemiology and Prevention, Council for High Blood Pressure Research, Council on Peripheral Vascular Disease, and Interdisciplinary Council on Quality of Care and Outcomes Research. Guidelines for the primary prevention of stroke: a guideline for healthcare professionals from 
the American Heart Association/American Stroke Association. Stroke. 2011; 42(2): 517-584, doi: 10.1161/STR.0b013e3181fcb238, indexed in Pubmed: 21127304.

6. Mao H, Lin P, Mo J, et al. Development of a new stroke scale in an emergency setting. BMC Neurol. 2016; 16: 168, doi: 10.1186/s12883016-0695-z, indexed in Pubmed: 27608839.

7. Byrne $B, O^{\prime}$ Halloran $P$, Cardwell C. Accuracy of stroke diagnosis by registered nurses using the ROSIER tool compared to doctors using neurological assessment on a stroke unit: a prospective audit. Int J Nurs Stud. 2011; 48(8): 979-985, doi: 10.1016/j.ijnurstu.2011.01.015, indexed in Pubmed: 21354569.

8. O'Donnell MJ, Xavier D, Liu L, et al. INTERSTROKE investigators. Risk factors for ischaemic and intracerebral haemorrhagic stroke in 22 countries (the INTERSTROKE study): a case-control study. Lancet.
2010; 376(9735): 112-123, doi: 10.1016/50140-6736(10)60834-3, indexed in Pubmed: 20561675.

9. Mackay MT, Churilov L, Donnan GA, et al. Performance of bedside stroke recognition tools in discriminating childhood stroke from mimics. Neurology. 2016; 86(23): 2154-2161, doi: 10.1212/ WNL.0000000000002736, indexed in Pubmed: 27178704.

10. Brandler ES, Sharma M, Sinert RH, et al. Prehospital stroke scales in urban environments: a systematic review. Neurology. 2014; 82(24): 2241-2249, doi: 10.1212/WNL.0000000000000523, indexed in Pubmed: 24850487.

11. Brandler ES, Sharma M, Khandelwal P, et al. Abstract WP243: Identification of Common Confounders in the Prehospital Identification of Stroke in Urban, Underserved Minorities. Stroke; a journal of cerebral circulation. 2013; 44(Suppl 1): AWP243-AWP243. 